\title{
Sken\&agraphie
}

SKrinagraphilu Coulisses des arts du spectacle et des scènes

émergentes

4| Automne 2016

Médée à l'opéra

\section{Présentation. Carlotta de Gilles Laubert}

\section{Julia Peslier et Pascal Lécroart}

URL : http://journals.openedition.org/skenegraphie/1303

DOI : 10.4000/skenegraphie.1303

ISSN : 2553-1875

\section{Éditeur}

Presses universitaires de Franche-Comté

\section{Édition imprimée}

Date de publication : 31 décembre 2016

Pagination : 111-113

ISBN : 978-2-84867-584-8

ISSN : $1150-594 \mathrm{X}$

\section{Référence électronique}

Julia Peslier et Pascal Lécroart, « Présentation. Carlotta de Gilles Laubert », Sken\&agraphie [En ligne] 4 | Automne 2016, mis en ligne le 05 juillet 2017, consulté le 21 avril 2019. URL : http:// journals.openedition.org/skenegraphie/1303 ; DOI : 10.4000/skenegraphie.1303

Ce document a été généré automatiquement le 21 avril 2019

Presses universitaires de Franche-Comté 


\title{
Présentation. Carlotta de Gilles Laubert
}

\author{
Julia Peslier et Pascal Lécroart
}

\section{L'auteur}

1 Né en 1950, Gilles Laubert se forme au métier d'acteur aux côtés de Jacques Vingler, à Besançon, puis à l'École Supérieure d'Art Dramatique de Genève et lors d'un stage à l'Odin Theatret danois. Acteur, metteur en scène et directeur de troupe, il a écrit également une vingtaine de pièces dont une large part est restée inédite. Sont parus, aux Solitaires intempestifs, les textes dramatiques L'Abus (2002) et Aminata (2012), tandis que les éditions Comp'Act de Chambéry avaient publié L'Heure du courage en 1996. Gilles Laubert est décédé brutalement en 2012.

2 Le fonds documentaire Gilles Laubert est consultable en ligne sur le site Fanum : http:// fanum.univ-fcomte.fr/laubert/index.php

3 La valorisation de son œuvre et sa bibliothèque ont été confiées au pôle "Arts et Littérature » de l'équipe de recherche ELLIADD (EA4661), sise à l'Université de FrancheComté, dans le cadre d'un projet animé par Pascal Lécroart.

\section{La pièce}

Carlotta, complétée par la mention manuscrite "Soliloque», prend place dans une trilogie, Elles parlent aux animaux, dont chaque partie se fonde sur un même dispositif : en un lieu du monde, une femme s'adresse à un animal en un puissant soliloque. Elles parlent aux animaux, c'est Denise, ouvrière horlogère exemplaire qu'on licencie à Besançon, dans des années proches des nôtres et qui finit par se venger. Pour se tenir compagnie, au départ de son dire, elle « installe un poisson rouge dans une petite verrine.» C'est alors que pour elle tout commence. Elle se lance. Elle parle, part du détail, du regard sur un monde miniature, pour ensuite dire son monde : «C'est petit hein ? C'est idiot c'est bête 
une petite verrine comme ça fermée avec juste un trou pour que tu respires! Pour un poisson comme toi ! Oh!... tu n'es pas bien grand mais sur le coup de l'achat, toute ma poitrine déjà elle bondissait d'amour de contentement !». C'est encore cette costumière de théâtre suisse qui, convertie au cœur de l'émeute, prend nom de Khadîdja, elle ou lui qui aurait dû avoir Georges comme nom de naissance, et qui a reçu Georgette, par sa mère, comme nom d'enfance. Face à elle et au costume qu'elle coud, dans une Genève contemporaine, son « rouchonnet des Colonies du Soleil», un canari tout ce qu'il y a de plus jaune, l'écoute. C'est enfin Carlotta, à Moscou, artiste du peuple qui doit se vendre pour les Variétés et déchoir d'une certaine idée du théâtre, pour racoler et faire sa confession publique, quand bien même tout en elle y répugne, sous la pression de directeurs peu consciencieux, avides de faire sensation. Elle doit d'ailleurs porter le frac, devenir Carlotto, exposer le secret de ses entrailles sur la scène et c'est de sa loge que nous sommes témoins de son bouillonnement intérieur. Dans sa loge, Lioubov, «Amour ", la petite mouette empaillée, l'assiste et assiste à son tourment, à son remords et à sa révolte intérieure.

5 Les animaux ne parlent pas. Ils sont pourtant au centre de la représentation, par la présence silencieuse, attentive. Ce sont elles, ces femmes qui défient les processus de déchéance, de mise à l'écart, d'enfermement dans lesquels on veut les circonscrire, qui leur parlent et disent le plus intime et le plus exposé de leur vie, depuis ces lieux des marges et des coulisses où elles œuvrent et ruminent leurs vies. Car chacune semble avoir plusieurs vies possibles, dans leur énonciation sans cesse recommencée.

6 Ces textes ont fait l'objet de différentes réécritures. Le Dit de Carlotta a connu une première version en 2001, avant d'être repris quelques années plus tard. Une première lecture en a été donnée par Dominique Favre-Bulle au Théâtre Monot de Beyrouth en octobre 2007.

7 À travers le personnage de Carlotta, Gilles Laubert travaille, comme à son habitude, les thématiques intimes et sexuelles d'un côté, sociales et politiques de l'autre. Ancienne grande actrice de la scène soviétique, Carlotta doit affronter le changement complet de situation professionnelle dû à la perestroïka et au triomphe du monde capitaliste face au naufrage de l'URSS. Ruinée et réduite à apparaître dans des shows télévisés à l'américaine, elle devra affronter publiquement un drame personnel terrible jusque-là caché : celui d'être responsable de la mort de son propre fils Gricha qu'elle a rejeté et dénoncé, n'acceptant pas son homosexualité.

8 Carlotta est composée de neuf tableaux, qui sont intitulés d'après une périodisation de la représentation, sur une scène médiatique, à laquelle nous n'assisterons pas: 1. Juste avant que cela commence -2 . Juste après son numéro - 3 . Juste après que du temps a passé - 4. Juste un peu plus tard - 5. Juste après quelques représentations et juste un peu avant la prochaine... - 6. Elle revient de scène, elle est en frac -7 . Juste après les nouvelles orientations et juste avant leur mise en œuvre (donc dans un entre deux) - 8. Juste avant de rentrer en scène $\mathbf{- 9}$. Juste après la représentation.

La pièce a été jouée par Dominique Favre-Bulle en février-mars 2009, au Théâtre SaintGervais de Genève, pour dix-huit représentations, en compagnie de Denise, jouée par Martine Paschoud, issue de la même trilogie. Khadîja sera écartée des représentations; retravaillé sous le titre Georges ou tout ce qui file entre ses doigts, ce soliloque sera créé deux ans plus tard par Gilles Laubert lui-même en scène, à Genève, au théâtre de la Traverse. Il 
existe une captation vidéo de ces spectacles produits par la Compagnie des Cris (consultable à la demande).

10 Suivent la didascalie initiale de Carlotta et les scènes 4, 5 et 6, telles qu'elles ont été retravaillées lors des répétitions. Nous remercions Mme Béatrice Cazorla, administratrice de la Compagnie des Cris, de nous avoir communiqué le texte et M. Jacques Bochaton de nous avoir autorisé à en reproduire ces extraits. 